\title{
Ação de dessecante na pré-colheita sobre a produtividade e a qualidade fisiológica de sementes crioulas de feijoeiro
}

\section{The effect of pre-harvest desiccation on the yield and physiological quality of landrace bean seeds}

\author{
Cileide Maria Medeiros Coelho ${ }^{\mathbf{1}^{*}}$; Clovis Arruda Souza²; \\ Marcio Zilio ${ }^{3}$; Adelina Ferreira Michels ${ }^{4}$
}

\begin{abstract}
Resumo
A antecipação da colheita pode diminuir o tempo em que as sementes permanecem no campo sob o risco de fatores bióticos e abióticos que podem promover sua deterioração. Assim, o presente trabalho teve como objetivo avaliar a antecipação da colheita e a qualidade fisiológica de sementes de feijão crioulo após a aplicação do herbicida paraquat em diferentes épocas de pré-colheita. O experimento foi realizado sob delineamento experimental inteiramente casualizado em esquema fatorial $3 \times 4$, com três repetições. O dessecante paraquat ( $400 \mathrm{~g} \mathrm{ha}^{-1}$ do i.a.) foi aplicado em plantas de feijoeiro, sendo dois genótipos crioulos 'BAF55' e 'BAF84' e um comercial 'BAF112' (IPR 88-Uirapurú) em três épocas $(26,30,34$ dias após a floração). O tratamento testemunha foi composto por plantas não dessecadas. Após a colheita, estimou-se a produtividade e em seguida foram realizados os testes de germinação, envelhecimento acelerado, comprimento de radícula, comprimento de hipocótilo e condutividade elétrica. A dessecação pré-colheita não afetou a produtividade, a germinação, o vigor e nem o desenvolvimento inicial de plântulas. A dessecação preservou a integridade das membranas celulares para os genótipos 'BAF112' e 'BAF55' quando o herbicida foi aplicado aos 26 DAF. No geral, as sementes dos genótipos crioulos de feijão apresentaram potencial fisiológico superior ao genótipo comercial na integridade de membranas. Os genótipos crioulos, 'BAF55' e 'BAF84' apresentaram maior produtividade de sementes que o comercial ('BAF112'). A dessecação pré-colheita possibilitou antecipar a colheita de 16 até 24 dias sem alterar a qualidade e a produtividade de sementes.
\end{abstract}

Palavras-chave: Phaseolus vulgaris, condutividade elétrica, envelhecimento acelerado, germinação, vigor

\begin{abstract}
An early harvest reduces the time that the seeds stay in the field under the effect of biotic and abiotic factors, which are responsible for their deterioration. So, the objective of this work was to determine the effect of pre-harvest desiccant application on the yield and physiological quality of common bean seeds. The experimental layout was completely random, the desiccant used was paraquat ( $400 \mathrm{~g} \mathrm{ha}^{-1}$ a.i.), on a combination of three genotypes: 'BAF55', 'BAF84' and 'BAF112' (commercial black cv. IPR88Uirapurú) with three plant desiccation periods (26, 30, 34 days after flowering (DAF)), and a control

${ }^{1}$ Prof ${ }^{a}$ Adjunto do Centro de Ciências Agroveterinárias, Universidade do Estado de Santa Catarina, CAV/UDESC, Lages, SC. E-mail: cileide@cav.udesc.br

${ }^{2}$ Prof. Associado do CAV/UDESC, Lages, SC. E-mail: souza_clovis@cav.udesc.br

${ }^{3}$ Doutorando no Programa de Pós-Graduação em Ciências Agrárias/Produção Vegetal, CAV/UDESC, Lages, SC. E-mail: marciozilio@gmail.com

${ }^{4}$ Mestranda no Programa de Pós-Graduação em Ciências Agrárias/Produção Vegetal, CAV/UDESC, Lages, SC. E-mail: adelinamichels@yahoo.com.br

* Autor para correspondência
\end{abstract}


(plants not desiccated). Post-harvest, productivity was estimated and, soon after, germination tests were carried out with and without accelerated ageing; main root radical length and hypocotyls length were measured as well as electrical conductivity. The desiccation maintenance the cell membrane integrity in the 'BAF112' and 'BAF55' genotypes when the paraquat was sprayed at 26 DAF. The results showed that the two landrace beans genotypes outperformed the commercial one in terms of seed yield and that the seeds produced were of higher physiological quality in terms of membrane integrity. The landraces 'BAF55' and 'BAF84' showed yield higher than commercial ('BAF112'). The early of the harvest through desiccant sprayed on plants 26 DAF did not adversely affect the yield or physiological quality of harvest bean seeds.

Key words: Phaseolus vulgaris, electrical conductivity, accelerated ageing, germination, vigor

A colheita da semente de feijão (Phaseolus vulgaris L.) deveria ser realizada logo após a maturidade fisiológica (MF), momento que as sementes apresentam elevado vigor, germinação e máximo acúmulo de matéria seca (SANTOS et al., 2005a). No entanto, nesta fase a semente apresenta elevado grau de umidade e a planta está com folhas e ramos verdes e úmidos. Isto associado aos diferentes hábitos de crescimento e de ramificações por planta em genótipos crioulos de feijão (COELHO et al., 2007) dificultaria que a colheita fosse realizada de modo eficiente.

Normalmente, as sementes permanecem no campo por um tempo superior a fase da maturidade fisiológica, e ficam expostas as variações ambientais de temperatura e umidade, que podem afetar negativamente a qualidade fisiológica das sementes (LACERDA et al., 2005), pois a perda e ganho de água na semente diminui seu potencial de germinação e vigor (MARCOS FILHO, 2005). Nesse sentido, a produção de sementes sob condições ambientais desfavoráveis à produtividade ou a baixa densidade específica das mesmas pode gerar sementes de baixa viabilidade (MUASYA; LOMMEN; STRUIK, 2002).

O feijão atinge sua maturidade fisiológica com grau de umidade acima de $25 \%$, tornando a colheita nessa época uma ação problemática, pois segundo Domingos, da Silva e da Silva (1997), o feijão quando debulhado com umidade acima de 18\%, apresenta danos latentes por amassamento. Sabendo que a melhor época para a colheita é quando a semente atinge a maturidade fisiológica e que a semente nesse período possui um elevado grau de umidade, faz-se necessário a adoção de práticas de manejo para reduzir a umidade rapidamente após as sementes atingirem a maturidade fisiológica.

A aplicação de herbicidas dessecantes é uma alternativa amplamente utilizada em campos de produção de sementes a fim de antecipar a colheita, minimizar a deterioração e a perda de qualidade no feijão (DOMINGOS; DA SILVA; DA SILVA, 1997) e, na soja (KAPPES; CARVALHO; YAMASHITA, 2009), por padronizar a maturação e a desidratação das plantas e sementes para possibilitar a colheita. Na cultura da soja, o uso de dessecante antecipa a colheita em até sete dias sem alterar a sua produtividade (KAPPES; CARVALHO; YAMASHITA, 2009) e poderá ser aplicada desde o estádio R6.5 das plantas para antecipar a colheita (em até 6 dias) e evitar a exposição das sementes as intempéries climáticas durante a fase de campo (DALTRO et al., 2010).

Entre os herbicidas registrados no Ministério da Agricultura, Pecuária e Abastecimento (BRASIL, 2010) são recomendados para dessecação química das plantas de feijão em pré-colheita os produtos: paraquat, dibrometo de diquate, flumioxazina e glufosinato sal de amônio. No entanto, em genótipos crioulos de feijão a dessecação pré-colheita de plantas com a finalidade de antecipar a colheita e preservar a qualidade fisiológica das sementes ainda não foi estudada.

O presente trabalho teve como objetivo avaliar a antecipação da colheita e a qualidade fisiológica (germinação e vigor) de sementes de feijão crioulo 
após a aplicação do herbicida paraquat em diferentes épocas de pré-colheita.

O experimento foi realizado no ano agrícola de 2008/2009, no município de Lages - SC, situado nas coordenadas geográficas $27^{\circ} 48^{\prime} 57^{\prime \prime}$
$\mathrm{S}, 50^{\circ} 19^{\prime} 33^{\prime \prime} \mathrm{W}$, com $930 \mathrm{~m}$ de altitude. Os valores das temperaturas (máxima, média e mínima) e a precipitação pluvial registradas durante a época de cultivo estão apresentadas na figura 1 (INMET, 2009).

Figura 1. Temperaturas, máxima, média e mínima e precipitação pluvial, ocorridas durante a época de cultivo do experimento sob condições de campo, safra 2008/2009. Setas representam respectivamente, datas de semeadura (SE), emergência (EM), floração (FL), 1 ${ }^{\mathrm{a}}, 2^{\mathrm{a}}$ e $3^{\mathrm{a}}$ aplicação de paraquat (1A, 2A e 3A) e colheita (CO).

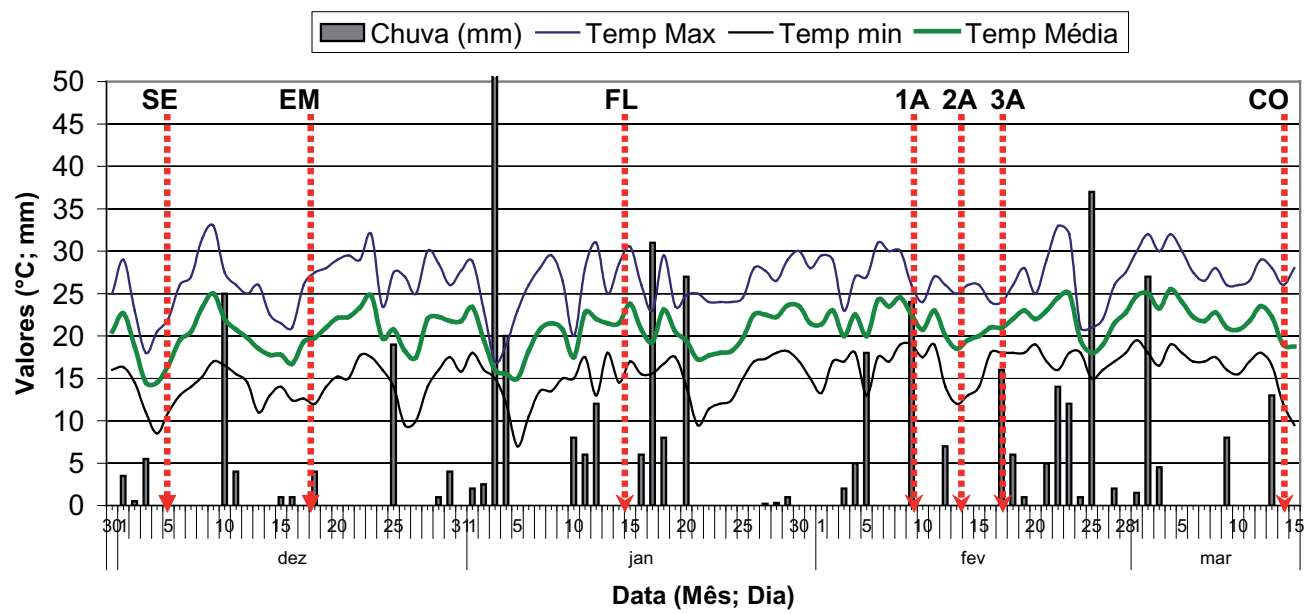

Fonte: Dados Meteorológicos de Lages SC provenientes do Instituto Nacional de Meteorologia (INMET, 2009).

A área experimental foi preparada via sistema convencional composto por uma aração seguida de uma gradagem. O solo classificado como Cambissolo alumínico com $\mathrm{pH}$ 5,5. Foi realizada a adubação de base previamente à semeadura de acordo com a análise de solo e as recomendações para a cultura do feijão, conforme está descrita na Comissão de Química e Fertilidade do Solo para RS e SC (CQFS-RS/SC, 2004).

O experimento foi instalado sob delineamento inteiramente ao acaso com três repetições, em esquema fatorial $3 \times 4$ (genótipos $\mathrm{x}$ épocas de dessecação). Os genótipos de feijão foram obtidos no Banco Ativo de Feijão (BAF) do Centro de Ciências Agroveterinárias da Universidade do Estado de Santa Catarina CAV/UDESC, sendo dois genótipos crioulos 'BAF55' [preto] e 'BAF84' [Carioca]) e um comercial 'IPR 88-Uirapuru', correspondente ao 'BAF112'.

As parcelas experimentais foram compostas por 4 linhas de 3 metros espaçadas $0,5 \mathrm{~m}$ entre elas, considerando-se como área útil as duas linhas centrais, desprezando $0,5 \mathrm{~m}$ de cada extremidade das linhas. Nas linhas foram semeadas 15 sementes por metro totalizando 45 sementes por linha. A semeadura foi realizada no dia 04/12/2008. As sementes foram tratadas com os fungicidas carbendazim+thiram na dosagem de $300 \mathrm{ml}$ p.c. para cada $100 \mathrm{~kg}$ de sementes e o inseticida imidacloprid $250 \mathrm{ml}$ para cada $100 \mathrm{~kg}$ de sementes respectivamente.

Nos estádios V4 (três trifólios) e R5 (início da floração) foram realizadas as adubações de cobertura, aplicando-se $30 \mathrm{~kg}$ de $\mathrm{N} \mathrm{ha}^{-1}$ em cada 
aplicação. O manejo da cultura, quanto a pragas, doenças e plantas daninhas, foi realizado de acordo com as necessidades, utilizando-se os produtos químicos recomendados para a cultura do feijão.

As plantas de feijão foram dessecadas com o herbicida paraquat (400 $\mathrm{g} \mathrm{ha}^{-1}$ do i.a.) aos 26 (10/02/2009), $30(14 / 02 / 2009)$ e $34(18 / 02 / 2009)$ dias após o pleno florescimento (15/01/2009). As parcelas do tratamento testemunha não sofreram a aplicação do herbicida dessecante, e foram colhidas após a secagem natural das plantas (58 DAF). As colheitas das plantas dessecadas ocorreram 8 dias após a aplicação do dessecante, 34, 38 e 42 DAF para as aplicações de dessecante aos 26, 30 e 34 DAF, respectivamente.

As sementes obtidas foram secas para a umidade de $12 \%$, e determinou-se a produtividade de cada genótipo, em $\mathrm{kg}$ ha- $^{1}$ com base na área útil da parcela. Posteriormente realizaram-se os testes de potencial fisiológico das sementes em laboratório. As sementes foram armazenadas em câmara seca com temperatura próxima a $8{ }^{\circ} \mathrm{C}$ e $40 \%$ de umidade relativa. Foram avaliados os seguintes parâmetros:

Teor de água das sementes (TAS): foi determinada a umidade de uma amostra de sementes no dia da aplicação do dessecante através do método da estufa a $105 \pm 3{ }^{\circ} \mathrm{C}$ por 24 horas, conforme indicado em RAS (BRASIL, 2009).

Germinação (G): realizado com quatro subamostras de 50 sementes provenientes da amostra de trabalho de cada tratamento distribuídas em rolos de papel germitest, umedecido com 2,5 vezes o peso do papel com água destilada e colocadas para germinar a $25{ }^{\circ} \mathrm{C}$. As porcentagens de germinação foram anotadas no $9^{\circ}$ dia após a instalação do teste, segundo as recomendações contidas nas Regras para Análise de Sementes (BRASIL, 2009).

Comprimento de radícula (CR): foi medido o comprimento da radícula de cada semente germinada após o $5^{\circ}$ dia do teste de germinação, com o auxilio de um paquímetro.
Comprimento de hipocótilo (CH): foi medido o comprimento do hipocótilo, entre o início do desenvolvimento das raízes e o ponto de inserção dos cotilédones no $5^{\circ}$ dia do teste de germinação, com o auxilio de um paquímetro.

\section{Teste de envelhecimento acelerado (TEA):} Foram utilizadas 4 subamostras de 50 sementes para cada tratamento. As sementes foram distribuídas sobre telas de alumínio, fixadas no interior de caixas plásticas adaptadas, onde foram adicionados 40 $\mathrm{mL}$ de água. As caixas foram tampadas e lacradas com filme de PVC (Royalpack ${ }^{\circledR}$ ) mantidas em estufa para envelhecimento, regulada a $42{ }^{\circ} \mathrm{C}$, onde permaneceram por 48 horas (AOSA, 1983). Após esse período, as sementes foram colocadas para germinar a $25{ }^{\circ} \mathrm{C}$ e após o $5^{\circ}$ dia foi realizada a contagem do número de plântulas normais.

Condutividade elétrica (CE): utilizaramse quatro amostras de 50 sementes para cada tratamento. As amostras foram pesadas em balança de precisão e, a seguir, colocadas para embebição em recipiente plástico contendo $75 \mathrm{~mL}$ de água destilada, sendo mantidas em estufa, à temperatura de $25^{\circ} \mathrm{C}$, durante 24 horas. Após esse período, fezse a leitura da condutividade elétrica na solução de embebição, utilizando-se um condutivímetro digital, cujos resultados foram expressos em $\mu \mathrm{S} \mathrm{cm}^{-1} \mathrm{~g}^{-1}$.

Os dados foram submetidos aos testes de Lilliefors (5\%), para verificar se seguiram a distribuição normal, e de Cochran e Bartlett (5\%), para verificar a homogeneidade de variâncias. Os dados de germinação e envelhecimento acelerado foram transformados por $(\mathrm{x}+1)^{0,5}$ previamente a análise de variância. Após a análise de variância (teste $\mathrm{F}$ a $5 \%$ de significância) as médias foram comparadas pelo teste Tukey a $5 \%$ de probabilidade. Após a análise de variância, pelo teste $\mathrm{F}(P<0,05)$, observou-se que apenas o teste de condutividade elétrica apresentou diferenças entre épocas de dessecação e entre genótipos e efeito simples de genótipo para a produtividade de semente (SAS, 2003). 
Ao comparar cada genótipo nas diferentes épocas de dessecação, o genótipo 'BAF55' apresentou o menor valor CE $\left(46,9 \mu \mathrm{S} \mathrm{cm}^{-1} \mathrm{~g}^{-1}\right)$ com dessecação aos $26^{\circ}$ dia após a floração (DAF) e maior CE $(69,4$ $\left.\mu \mathrm{S} \mathrm{cm}^{-1} \mathrm{~g}^{-1}\right)$ quando não foi aplicado dessecante (Tabela 1). Entretanto não houve diferença entre o tratamento testemunha (sem aplicação) e os tratamentos com dessecante aplicado aos 30 e 34 DAF. Entre os genótipos avaliados, o 'BAF 55' manteve sua qualidade fisiológica em função da menor condutividade aos $26^{\circ} \mathrm{DAF}$, devido a menor liberação de solutos e melhor integridade de membrana.

Foi observado no genótipo 'BAF112', que a menor CE foi aos $26^{\circ} \operatorname{DAF}\left(56,5 \mu \mathrm{S} \mathrm{cm}^{-1} \mathrm{~g}^{-1}\right)$ e a maior $\mathrm{CE}$ quando não foi aplicado o dessecante $\left(89,7 \mu \mathrm{S} \mathrm{cm} \mathrm{cm}^{-1} \mathrm{~g}^{-1}\right)$. No genótipo 'BAF 84 ' os tratamentos não influenciaram a condutividade elétrica das sementes.

Considerando o efeito simples de genótipo, quanto ao resultado de CE, o genótipo 'BAF84' se destacou $\left(46,3 \mu \mathrm{S} \mathrm{cm} \mathrm{cm}^{-1}\right)$, comparado ao genótipo 'BAF55' $\left(55,7 \mu \mathrm{S} \mathrm{cm}^{-1} \mathrm{~g}^{-1}\right)$ e o genótipo IPR-Uirapurú $\left(70,9 \mu \mathrm{S} \mathrm{cm}^{-1} \mathrm{~g}^{-1}\right)$, diferiram entre si (Tabela 1). Este resultado evidencia que os dois genótipos crioulos têm superior capacidade de preservar a integridade de membrana, ou seja, apresentaram maior potencial fisiológico das sementes. As diferenças quanto as condutividades entre genótipos já foi previamente constatada em estudos prévios com genótipos crioulos (COELHO et al., 2010) e cultivares comerciais e linhagens (KIKUTI et al., 2006).

Tabela 1. Condutividade elétrica, produtividade de sementes, teste padrão de germinação e teste de envelhecimento acelerado das sementes de três cultivares de feijoeiro provenientes de plantas dessecadas em diferentes épocas de précolheita. Safra 2008/2009.

\begin{tabular}{|c|c|c|c|c|}
\hline & \multicolumn{3}{|c|}{ Cultivares } & \multirow[b]{2}{*}{ Média } \\
\hline & 'BAF55' & 'BAF84' & 'BAF112' & \\
\hline${ }^{1 / D A F}$ & \multicolumn{3}{|c|}{ Condutividade Elétrica } & \\
\hline 26 & B 46,91 a & A 42,39 a & B $56,50 \mathrm{a}$ & B 49,21 \\
\hline 30 & $\mathrm{AB} 50,06 \mathrm{ab}$ & A 41,24 b & B 58,88 a & В 50,06 \\
\hline 34 & A $56,59 \mathrm{ab}$ & A 50,12 b & B 67,37 a & B 58,03 \\
\hline Sem aplicação & A $69,41 \mathrm{ab}$ & A $52,64 \mathrm{~b}$ & A $89,73 \mathrm{a}$ & A 70,37 \\
\hline \multirow[t]{2}{*}{ Média } & $55,74 \mathrm{~b}$ & $46,28 \mathrm{c}$ & 70,89 a & \\
\hline & \multicolumn{3}{|c|}{ Produtividade de Sementes } & \\
\hline \multirow[t]{2}{*}{ Média } & $1930 \mathrm{a}$ & $1949 \mathrm{a}$ & $962 \mathrm{~b}$ & \\
\hline & \multicolumn{3}{|c|}{ Germinação } & \\
\hline Teste de Germinação & A 97,8 a & A $98,4 \mathrm{a}$ & A 98,0 a & A 98,1 \\
\hline Teste de Envelhecimento Acelerado & B 33,0 a & B $20,4 \mathrm{a}$ & B 18,1 a & B 23,8 \\
\hline
\end{tabular}

1/Dias Após a Floração em que foi aplicado o dessecante.

Médias seguidas pela mesma letra, maiúsculas na coluna e minúsculas na linha, não diferem entre si pelo teste de Tukey, a 5\% de probabilidade de erro.

Fonte: Elaboração dos autores. 
A aplicação do dessecante aos 26 e 30 DAF nas plantas do genótipo 'BAF55' a aos 26, 30, e 34 DAF nas plantas do genótipo 'BAF112' favoreceu a qualidade fisiológica da semente pela variável de condutividade elétrica quando comparadas as sementes das plantas não dessecadas. Os menores valores de $\mathrm{CE}$ indicam maior integridade das membranas celulares e menor liberação de solutos. A baixa liberação de solutos após a semeadura, significa menor perda de compartimentalização celular, que poderá sob condições de campo minimizar o crescimento de micro-organismos nocivos à emergência das plântulas (MARCOS FILHO, 2005). Em adição, observou-se que o teste de condutividade elétrica foi eficiente na detecção das diferenças entre os tratamentos avaliados, o que corrobora com os resultados obtidos por Coelho et al. (2010) e Kikuti et al. (2006).

Os resultados obtidos no experimento estão de acordo com o que foi proposto por Marcos Filho (2005), em que após a maturidade fisiológica poderá ocorrer desestruturação do sistema de membranas da semente, que se agrava com o maior intervalo de tempo de colheita em decorrência de condições adversas no campo. Em outra pesquisa, foi evidenciado que as primeiras sementes formadas numa mesma planta apresentam maior viabilidade (MUASYA; LOMMEN; STRUIK, 2002). Este resultado ressalta a importância de ser proceder a dessecação das plantas para antecipação da colheita, visando priorizar e preservar as sementes de maior viabilidade ou evitar a deterioração, principalmente das sementes oriundas das vagens que foram formadas das primeiras flores efetivas.

A produtividade e os parâmetros fisiológicos das sementes: percentual de germinação $(95,5 \%)$, comprimento de radícula $(10,8 \mathrm{~cm})$ e comprimento do hipocótilo $(1,15 \mathrm{~cm})$ não foram afetados pela dessecação das plantas em pré-colheita (Tabela 1). Entretanto, observou-se resposta diferenciada dos genótipos quanto à produtividade, sendo os genótipos crioulos superiores em $977 \mathrm{~kg} \mathrm{ha}^{-1}$ ao genótipo comercial (Tabela 1).
Entretanto, Kamikoga et al. (2009), encontraram efeito linear sobre a produtividade de grãos, na medida que a dessecação foi realizada aos 28, 33 e 43 após o pleno florescimento, com uma diferença aproximada de $140 \mathrm{~kg} \mathrm{ha}^{-1}$, de maneira independente da dessecação ou não, sendo a colheita realizada aos $28+10,33+10$ e $43+10$ dias, respectivamente. Entretanto, o caráter produtividade é dependente do genótipo, da safra e do ambiente, bem como da interação entre estes fatores, realizado através das avaliações de adaptabilidade e estabilidade (ROCHA et al., 2010).

A qualidade das sementes foi evidenciada também após o teste de envelhecimento acelerado, pois observou-se um decréscimo acentuado no porcentual de germinação em função do estresse causado por elevada temperatura e umidade, se comparado às sementes não envelhecidas, uma diferença de $63 \%$ (24,5\% x 98,1\%), porém, não se observou diferença entre os genótipos. A ausência de diferença entre os tratamentos pode ser indicativo que a dessecação das plantas não favorece o processo de degradação, como foi observado por outros autores, avaliando sementes oriundas de plantas dessecadas e submetidas ao armazenamento por 8 meses, nas quais constataram valores de germinação e vigor menores para todos os tratamentos de dessecação em comparação às sementes oriundas de plantas que não foram dessecadas (PENCKOWSKI; PODOLAN; LÓPEZ-OVEJERO, 2005).

Apesar das vantagens da aplicação de dessecante na pré-colheita, encontram-se divergências na literatura a este respeito. Segundo Teofilo, Medeiros Filho e Andrade (1999) a dessecação deve ser realizada aos 49 e 50 dias após o florescimento para maximizar a produtividade de grãos de feijão, em cultivar com ciclo de 109 dias, entretanto não antecipou da colheita, mas reduziu o grau de umidade dos grãos. Já Santos et al. (2004), empregaram o dessecante carfentrazone-ethyl na dose de 10 e $30 \mathrm{~g} \mathrm{ha}^{-1}$ i.a. aos $30 \mathrm{DAF}$, e observaram que este não afetou a produtividade, mas a antecipação da colheita em sete dias. Tais resultados contrastantes 
na literatura podem ser decorrentes do produto químico como foi o caso de paraquat (400 g ha- ${ }^{1}$ do i.a.) e paraquat+diquat $\left(250+125 \mathrm{~g} \mathrm{ha}^{-1}\right.$ do i.a.) (TEOFILO; MEDEIROS FILHO; ANDRADE, 1999) e carfentrazone-ethyl (10 e $30 \mathrm{~g} \mathrm{ha}^{-1}$ i.a.) (SANTOS et al., 2005b), bem como da cultivar, duração do estágio reprodutivo e também do estádio fenológico do feijão ideal para a aplicação do dessecante, sendo este o estádio R8 (DOMINGOS; DA SILVA; DA SILVA, 1997; MARCOS FILHO, 2005; SANTOS et al., 2005b).

Além dos fatores relacionados com o tipo e épocas de aplicação do dessecante, as condições climáticas podem alterar a eficiência do uso do mesmo. Neste aspecto, realizou-se o levantamento das condições climáticas ocorridas no experimento (Figura 1), pois ocorreram 15 dias consecutivos desfavoráveis ao processo de maturação, devido ao excesso hídrico ocorrido quando as plantas foram dessecadas no $34^{\circ}$ DAF e aquelas mantidas para ocorrer a secagem natural (testemunha), período compreendido de 17 de fevereiro a 03 de março de 2009. Estas plantas foram expostas a $127 \mathrm{~mm}$ de precipitação pluvial acumulada, com 12 dias com chuva entre os 15 dias. Como consequência disto, a necessidade de se esperar mais 11 dias para a colheita final do experimento ocorrida em 14 de março. Entretanto, tais condições ambientais não afetaram negativamente a qualidade fisiológica das sementes. Também foi possível uma antecipação da colheita em 16, 20 e 24 dias pela dessecação com paraquat. É importante ressaltar que na época de maturação, as plantas permaneceram expostas a condições desfavoráveis a perda de umidade das plantas, tanto pela quantidade acumulada de chuvas como devido às temperaturas amenas com média situada ente 20 e $25^{\circ} \mathrm{C}$ (Figura 1). Mas, mesmo assim a qualidade fisiológica das sementes foi mantida.

A dessecação pré-colheita não afetou a produtividade, a germinação, o vigor e nem o desenvolvimento inicial de plântulas. A dessecação preservou a integridade das membranas celulares para os genótipos 'BAF112' e 'BAF55' quando o herbicida foi aplicado aos 26 DAF. No geral, as sementes dos genótipos crioulos de feijão apresentaram potencial fisiológico superior ao genótipo comercial na integridade de membranas. Os genótipos crioulos, 'BAF55' e 'BAF84' apresentaram maior produtividade de sementes que o comercial ('BAF112'). A dessecação précolheita possibilitou antecipar a colheita de 16 até 24 dias sem alterar a qualidade e a produtividade de sementes.

\section{Agradecimentos}

A CAPES (Coordenação de Aperfeiçoamento de Pessoal de Nível Superior) pelo apoio financeiro via PRODOC (Programa de Apoio a Projetos Institucionais).

\section{Referências}

ASSOCIATION OF OFFICIAL SEED ANALYSTS - AOSA. Seed vigor testing handbook. East Lansing: AOSA, 1983. 93 p. (Contribution, 32).

BRASIL. Ministério da Agricultura, Pecuária e Abastecimento. Regras para análise de sementes. Ministério da Agricultura, Pecuária e Abastecimento. Secretaria de Defesa Agropecuária. Brasília: MAPA/ ACS, 2009. 399 p.

. Herbicidas - consulta de ingrediente ativo agrofit. Brasília, DF: MAPA/SDA/AGROFIT, 2010. Disponível em: <http://extranet.agricultura.gov.br/ agrofit_cons/principal_agrofit_cons $>$. Acesso em: 25 set. 2010.

COELHO, C. M. M.; COIMBRA, J. L. M.; SOUZA, C. A.; BOGO, A.; GUIDOLIN, A. F. Diversidade genética em acessos de feijão (Phaseolus vulgaris L.) Ciência Rural, Santa Maria, v. 37, n. 5, p. 1241-1247, 2007.

COELHO, C. M. M.; MOTA, M. R.; SOUZA, C. A.; MIQUELLUTI, D. J. Potencial fisiológico em sementes de cultivares de feijão crioulo (Phaseolus vulgaris L.). Revista Brasileira de Sementes, Londrina, v. 32, n. 3, p. 97-105, 2010.

COMISSÃO DE QUÍMICA E FERTILIDADE DO SOLO - CQFS-RS/SC. Manual de adubação e de calagem para os estados do Rio Grande do Sul e Santa Catarina. 10. ed. Porto Alegre: SBCS - Núcleo Regional Sul/UFRGS, 2004. 400 p. 
DALTRO, E. M. F.; ALBUQUERQUE, M. C. F.; FRANÇA NETO, J. B.; GUIMARAES, S. C.; GAZZIERO, D. L. P.; HENNING, A. A. Aplicação de dessecantes em pré-colheita: efeito na qualidade fisiológica de sementes de soja. Revista Brasileira de Sementes, Londrina, v. 32, n. 1, p. 111-122, 2010.

DOMINGOS, P.; DA SILVA, A. A.; DA SILVA, R. F. Qualidade da semente de feijão afetada por dessecantes, em quatro estádios de aplicação. Revista Brasileira de Sementes, Londrina, v. 19, n. 2, p. 275-282, 1997.

INSTITUTO NACIONAL DE METEOROLOGIA INMET. Boletim Agroclimatológico: mapas do boletim agroclimatológico. 2009. Disponível em: <http://www. inmet.gov.br/climatologia/bol_agro/mapas.php>. Acesso em: 11 maio 2009.

KAMIKOGA, A. T. M.; KAMIKOGA, M. K.; TERASAWA, J. M.; ROMANEK, C.; PENKAL, K. F. Efeito de diferentes épocas de aplicação de três herbicidas dessecantes na produção e qualidade fisiológica de sementes de feijão. Publicatio UEPG Ciências Exatas e da Terra, Ciência Agrárias e Engenharia, Ponta Grossa, v. 15, n. 1, p. 53-61, 2009.

KAPPES, C.; CARVALHO, M. A. C. D.; YAMASHITA, O. M. Potencial fisiológico de sementes de soja dessecadas com diquat e paraquat. Scientia Agraria, Curitiba, v. 10, n. 1, p. 1-6, 2009.

KIKUTI, H.; ANDRADE, M. J. B.; KIKUTI, A. L. P.; PEREIRA, C. E. Qualidade de sementes de genótipos de feijão em função da adubação. Revista Ciência Agronômica, Fortaleza, v. 37, n. 1, p. 37-46, 2006.

LACERDA, A. L. S.; LAZARINI, E.; SÁ, M. E.; VALÉRIO FILHO, W. V. Efeitos da dessecação de plantas de soja no potencial fisiológico e sanitário das sementes. Bragantia, Campinas, v. 64, n. 3, p. 447-457, 2005.

MARCOS FILHO, J. Fisiologia de sementes de plantas cultivadas. Piracicaba: FEALQ, 2005. 495 p.
MUASYA, R. M.; LOMMEN, W. J. M.; STRUIK, P. C. Differences in development of common bean (Phaseolus vulgaris L.) crop and fractions within a crop: II. Seed viability and vigour. Field Crop Research, Amsterdam, v. 75 , n. 1, p. 79-89, 2002.

PENCKOWSKI, L. H.; PODOLAN, M. J.; LÓPEZOVEJERO, R. F. Efeito de herbicidas aplicados na précolheita na qualidade fisiológica das sementes de feijão. Revista Brasileira de Herbicidas, Passo Fundo, v. 4, n. 2, p. 102-113, 2005.

ROCHA, V. P. C.; MODA-CIRINO, V.; DESTRO, D.; FONSECA JÚNIOR, N. S.; PRETE, C. E. C. Adaptabilidade e estabilidade da característica produtividade de grãos dos grupos comerciais carioca e preto de feijão. Semina: Ciências Agrárias, Londrina, v. 31, n. 1, p. 39-54, 2010.

SANTOS, J. B.; FERREIRA, E. A.; FERREIRA, E. M.; SILVA, A. A.; FERREIRA, L. R. Efeitos da dessecação de plantas de feijão sobre a qualidade de sementes armazenadas. Planta Daninha, Viçosa, v. 23, n. 4, p. 645651, 2005a.

SANTOS, J. B.; FERREIRA, E. A.; SANTOS, E. A.; SILVA, A. A.; SILVA, F. M.; FERREIRA, L. R. Qualidade de sementes de feijão (Phaseolus vulgaris) após aplicação do carfentrazone-ethyl em pré-colheita. Planta Daninha, Viçosa, v. 22, n. 4, p. 633-639, 2004.

SANTOS, J. B.; FERREIRA, E. A.; SILVA, A. A.; SILVA, F. M.; SANTOS, E. A.; FERREIRA, L. R. Avaliação do carfentrazone-ethyl como dessecante em pré-colheita de sementes de feijão (Phaseolus vulgaris L.). Revista Ceres, Viçosa, v. 53, n. 304, p. 831-843, 2005 b.

SAS Institute. SAS Institute Inc ${ }^{\circledR}$. 2003. Cary, NC, USA, Licence UDESC: SAS Institute Inc, 2003.

TEOFILO, E. M.; MEDEIROS FILHO, S.; ANDRADE, M. J. B. Ação de dessecantes sobre o feijoeiro cultivado no inverno-primavera. Revista Ceres, Viçosa, v. 46, n. 267, p. 471-492, 1999. 